\title{
Atomistic Study on Size Effects in Thermally Induced Martensitic Phase Transformation of NiTi
}

\author{
Sourav Gur and George N. Frantziskonis \\ Department of Civil Engineering and Engineering Mechanics, University of Arizona, Tucson, AZ 85721, USA
}

Correspondence should be addressed to George N. Frantziskonis; frantzis@email.arizona.edu

Received 23 July 2016; Revised 7 September 2016; Accepted 18 September 2016

Academic Editor: Yong Liu

Copyright (C) 2016 S. Gur and G. N. Frantziskonis. This is an open access article distributed under the Creative Commons Attribution License, which permits unrestricted use, distribution, and reproduction in any medium, provided the original work is properly cited.

\begin{abstract}
The atomistic study shows strong size effects in thermally induced martensitic phase transformation evolution kinetics of equiatomic NiTi shape memory alloys (SMAs). It is shown that size effects are closely related to the presence of free surfaces; thus, NiTi thin films and nanopillars are studied. Quasi-static molecular dynamics simulations for several cell sizes at various (constant) temperatures are performed by employing well-established interatomic potentials for NiTi. The study shows that size plays a crucial role in the evolution of martensite phase fraction and, importantly, can significantly change the phase transformation temperatures, which can be used for the design of NiTi based sensors, actuators, or devices at nano- to microscales. Interestingly, it is found that, at the nanometer scale, Richard's equation describes very well the martensite phase fraction evolution in NiTi thin films and nanopillars as a function of temperature.
\end{abstract}

\section{Introduction}

Shape memory alloys (SMAs) form a particular class of materials that can recover a high level of inelastic or residual strain (up to 8\%) through martensitic phase transformation upon heating. SMAs such as NiTi also show superelasticity associated with mechanical loading above a certain critical temperature, that is, the austenite finish temperature $A_{f}$, where deformation can be fully recovered upon unloading without any application of heat. Among different SMAs, NiTi is a popular one due to its unique shape recovery capability and high energy dissipation potential through the reversible phase transformation process. Phase transformation in NiTi is diffusionless and displacive in nature [1-4], where one particular type of crystal structure (austenite) transforms to another (martensite) from the application of heat and/or stress/strain. Due to the aforementioned aspects NiTi has found applications in a wide range of fields and at scales ranging from nano- to macrocontinuum level [1,5-7].

It has been well-established that the behavior of $\mathrm{NiTi}$ SMA depends highly on the instantaneous martensite phase fraction and its growth rate. Within its typical operating temperature range, NiTi consists of two phases: (a) the high temperature phase of high symmetry cubic B2 crystal structure, called austenite, and (b) the low temperature phase of a combination of different low symmetry monoclinic variants (up to 12 variants) of $\mathrm{B}^{\prime} 9^{\prime}$ crystal structure, called martensite [8-12]. The martensitic phase transformation process (B2 $\rightarrow$ $\left.\mathrm{B} 19^{\prime}\right)$ involves shear driven lattice distortion of B2 crystals, and occurs via an underlying phonon instability due to the softening of a specific transverse acoustic $\left(\mathrm{TA}_{2}\right)$ branch in its phonon dispersion band structure [1-4]. During the process of displacive transformation, NiTi B2 crystals undergo shear lattice distortion due to the combination of shear along

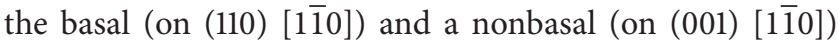
planes and transforms into the monoclinic B19' (martensite) phase [1,13-17]. Such transformation occurs over a range of temperatures, where, during the cooling process, the transformation temperature decreases continuously (specifically below the martensite start $\left(M_{s}\right)$ temperature) [1, 13-17]. In terms of thermodynamics, whenever B2 transform into B19', the total free energy of the system $\left(\mathrm{B} 2+\mathrm{B} 19^{\prime}\right)$ increases as the developed internal strain increases the strain energy. Thus, to advance the transformation process, the temperature needs to decrease, and this reduces the total free energy of the system, thereby increasing the driving force on the remaining 
$\mathrm{B} 2$ to transform into ${\mathrm{B} 19^{\prime}}^{\prime}[18,19]$. Thus, to understand the martensitic phase transformation in NiTi SMA, it is very important to have knowledge of the evolution kinetics of various phases at the atomic level.

The crystal structure of the NiTi SMA austenite phase (B2) is cubic, whereas, martensitic $\left({\mathrm{B} 19^{\prime}}^{\prime}\right)$ crystals can have different orientation directions, forming the so-called variants. The phase transition from austenite (B2) to martensite $\left(\mathrm{B}^{\prime} 9^{\prime}\right)$ results in the formation of several martensitic variants, up to 12 for NiTi [8-12], and the assembly of martensitic variants can exist in the form of twinned martensite (i.e., martensite variant compatible in terms of deformation gradient) [11, 20-22]. These twins are classified as type I twin, type II twin and compound twin [11, 20-22]. In type I the twin plane is a rational crystallographic plane, whereas in type II the twin shear is a rational crystal direction, and in the compound twin both the twin plane and twin shear are rational [11, 20-24]. Evolution of twin martensite variants strongly depends on the grain size. In coarse-grained $\mathrm{NiTi}$ type I and II twins are more noticeable than compound twins, which is due to deformation compatibility requirements for the habit planes that is, in between the interface of austenite and different martensite variants [11, 20-24]. These compound twins are typically observed in nanocrystalline $\mathrm{NiTi}$, where they are generally present at the nanoscale. It has been observed from different studies at the nanometer level [11, 20-25] that martensitic phase transformation kinetics are strongly influenced by the nanostructural size, twin boundary energy, grain boundary energy, and the elastic energy of twin variants and of surrounding matrix [11, 20-25].

From the above, it is clear that at the atomic level (nanometer scale) the martensite phase fraction evolution and phase transformation kinetics (nucleation and growth of different ${\mathrm{B} 19^{\prime}}^{\prime}$ variants) $[11,20-25]$ depend strongly on the microstructure of NiTi SMA. Further, the complexity in the phase transformation process increases when free surfaces are introduced at the atomic scale. Free surfaces act as defects, thus changing the total free energy of the NiTi system per unit volume, thereby helping the phase transformation activation process. These, known as surface effects, affect the phase transformation process and result in size effects [26-29]. Recent experimental studies show that the presence of free surfaces at the nano- to micrometer scale in NiTi and other SMAs [20-25, 30, 31] substantially change the phase transformation kinetics (i.e., evolution of different phases) and thus the overall material properties as compared to its properties at bulk scales. Examples include (a) evolution of unique martensite microstructure in terms of compound twins through entire NiTi nanograins [21, 22]; (b) NiTi nanograins exhibiting superelasticity with small hysteresis loops [24, 32]; and (c) CuAlNi thin films and nanopillars showing two-way shape memory effect and high damping capacity [33]. In addition to experiments, classical MD simulations have been performed at the nanometer scale, on different NiTi structural components. Studies show, at such scales, remarkable differences in transformation dynamics and phase evolution kinetics compared to at bulk scales $[34,35]$ and that material properties depend strongly on the NiTi nanostructure or morphology [21, 22, 30, 36, 37].
Examples include (a) equiatomic NiTi thin films [30, 36, 38] and nanowires $[24,39]$ showing high possibility of evolution (nucleation and growth) of unexpected stable crystal structures during phase transformation; (b) multiple transformation paths from $\mathrm{B} 2$ to $\mathrm{B}^{\prime} 9^{\prime}[21,22,25]$; and (c) highly stable square nanowires against torsional buckling, as compared to circular ones [39]. Therefore, at nano- to micrometer level, length scales in conjunction with the presence of free surfaces tailor the microstructure evolution, thereby changing the phase transformation temperature and the temperature dependency of the phase fraction evolution process. Variations in the phase transformation process at the atomic level can finally alter the properties of NiTi at macroscales.

The microstructure or morphology based unique behavior of NiTi at nano- or micrometer length scales makes it an attractive choice in the field of sensors, actuators, composites, or devices for medical and other applications [1, 5-7, 4043], where certain functionalities at certain length scales are required. Several studies address the surface and size effects at the atomic scale in the NiTi phase transformation process, attempting to provide more physics-based material models. Only studies relevant to this work are cited herein. A very recent study based on classical MD shows size effects at the atomic scale, in both the austenitic and martensitic phase transformation process of NiTi nanoparticles [25, 31]. Experimental studies at the nanometer and micrometer length scales, for different structures such as thin films [30, 36], nanoparticles [25, 31], and nanopillars [23, 24, 44], report the presence of strong size effects on the thermally induced martensitic phase transformation process. They mainly address surface and/or size effects in (a) transformation induced morphologies or microstructure of NiTi and (b) phase transformation process. Further, experimental studies on NiTi thin films show the effect of thickness on thermally induced phase transformation [38]. Other studies report a critical system size below which phase transformation will not occur in NiTi [25].

Motivation, Objective, and Brief Description of the Present Work. As mentioned above, extensive computational and experimental studies address the thermally induced martensitic phase transformation process. Of particular interest, some of those studies demonstrate the effect of size on the phase transformation process at the nanometer scale. Studies based on MD simulations [11, 24, 25, 31, 45] involve thermal cycles, where the temperature changes continuously with certain temperature rate ( 1 to $4 \mathrm{~K} / \mathrm{ps})$. Experimental studies [46-49] show that the temperature rate can cause systematic shift in the phase transformation temperatures. Martensite start $\left(M_{s}\right)$ and finish $\left(M_{f}\right)$ temperatures decrease with increasing temperature rate, thereby changing the temperature dependency of martensite phase fraction evolution. Other experimental studies [37, 38, 50-52] (in case of NiTi thin films) report that formation of surface oxide and interfacial diffusion layers between NiTi and a silicon substrate surface constrain the phase transformation process. Thus, while previous studies at the nanometer scale provide valuable information about the phase transformation process (temperature dependency of phase fraction evolution and 
transformation temperatures) in NiTi SMA, they do not solely study size effects, since they include parameters such as temperature rate in size effects. The present study isolates (from temperature rates and other parameters) size effects in thermally induced martensitic phase transformation process of NiTi SMA and also reports the effects of size on the transformation temperature. For this, quasi-static atomistic simulations are performed at constant temperature (so that no temperature rate is involved) using a well-established interatomic potential for $\mathrm{NiTi}$ [53] based on a classical MD simulation platform [54, 55]. Two components, thin films and nanopillars, are examined, which are also found in many applications [1, 5-7, 40-43, 56].

\section{Methods}

Important to the simulations is materials characterization, that is, the method used to identify spatial domains of austenite and martensite during the thermally induced phase transformation. This section describes the materials characterization process used within the MD simulation process adopted herein and executed in LAMMPS $[46,47]$.

2.1. Interatomic Potential. An effective MD simulation framework for NiTi binary alloy based on the Finnis-Sinclair many-body interatomic potential has been proposed and examined in detail [11, 23, 24, 31, 39, 44, 45, 53, 57-59]. For self-containment, a brief and relevant description of this semiempirical interatomic MD potential is provided here, yet more detailed information can be found elsewhere [11, 23, 24, 31, 39, 44, 45, 53, 57-59]. Lai and Liu [53] developed this semiempirical interatomic potential based on experimental data and first principal calculations. It is based on the embedded-atom method (EAM) considering a secondmoment approximation of tight-binding theory (TBSMA).
The TBSMA is used for $\mathrm{Ni}-\mathrm{Ni}$ and $\mathrm{Ti}-\mathrm{Ti}$ interaction and mixed rule is used for the NiTi interaction. All the parameters in the Lai and Liu [53] interatomic potential are calculated from lattice parameters, cohesive energy, elastic constants, and vacancy formation energy of B2 structure [11, 53]. Employing this potential, reversible phase transformation between austenite (B2) and martensite $\left(\mathrm{B}^{\prime} 9^{\prime}\right)$ structures is observed. It has been confirmed that structurally stable B2 and $\mathrm{B} 19^{\prime}$ phases are obtained with low potential energy. In particular the cohesive energy of $\mathrm{B}^{\prime} 9^{\prime}$ variants is found to be more stable than that of B2 $[57,58]$.

According to this potential, the total energy of the system over all atoms is expressed as

$$
E_{t}=\sum_{i}\left\{\sum_{i \neq j} E\left(r_{i j}\right)-\sqrt{\sum_{i \neq j} F\left(r_{i j}\right)}\right\},
$$

where the first term in the right hand side indicates the pairwise interaction energy due to Born-Mayer repulsion, which stabilizes the crystal, and the second term represents many-body effects, considering second-moment approximation for the electron density. Recently the many-body interaction part of Lai and Liu potential has been modified by Zhong et al. [11]. In particular, a smooth cutoff behavior is considered to avoid the diverging forces (generated from large atomic displacements) during simulations. Such modification ensures the continuity of the second term in (1) and its first derivative at cutoff radius $\left(r_{c}\right)$ and hence provides smooth behavior in energies and interatomic forces molecular static and dynamic simulations. Different parameters of this modified interatomic potential are determined by fitting properties, obtained from first principles calculations, of the $\mathrm{B} 2$ phase at $0 \mathrm{~K}$, with the potential cutoff radius $r_{c}=4.2 \AA$. The terms in (1) are expressed as

$$
\begin{array}{ll}
E\left(r_{i j}\right)=A_{\alpha \beta} \exp \left[-p_{\alpha \beta}\left(\frac{r_{i j}}{d_{\alpha \beta}}-1\right)\right], & \\
F\left(r_{i j}\right)= \begin{cases}\sum_{i \neq j} \xi_{\alpha \beta}^{2} \exp \left[-2 q_{\alpha \beta}\left(\frac{r_{i j}}{d_{\alpha \beta}}-1\right)\right] & \text { for } r_{i j} \leq r_{1} \\
c_{0, \alpha \beta}+c_{1, \alpha \beta}\left(r_{i j}-r_{1}\right)+c_{2, \alpha \beta}\left(r_{i j}-r_{1}\right)^{2}+c_{3, \alpha \beta}\left(r_{i j}-r_{1}\right)^{3} & \text { for } r_{1} \leq r_{i j} \leq r_{c},\end{cases}
\end{array}
$$

where $i$ and $j$ denote atoms and $\alpha, \beta$ denote type of atoms $(\mathrm{Ni}$ or $\mathrm{Ti}$ ) and $r_{1}=4.0 \AA$. A detailed description of the parameters involved in this interatomic potential is provided in Zhong et al. [11, 23].

2.2. Simulation Details. Quasi-static MD simulations are performed in LAMMPS [54, 55], for temperature driven martensitic phase transformation in NiTi. Two types of simulation cells are considered: (a) 2D square thin films and (b) 3D nanopillars, with free (nonperiodic) boundary conditions in all directions. For the thin films, seven different sizes are simulated, that is, of side $2,4,8,16,32$, and $64 \mathrm{~nm}$, and the film thickness is kept constant at $2 \mathrm{~nm}$ for all sizes. Similarly, seven different sizes of $3 \mathrm{D}$ nanopillars were simulated, that is, of diameters $2,4,8,16,32$, and $64 \mathrm{~nm}$ and length $8 \mathrm{~nm}$ with nonperiodic boundaries in all directions. To demonstrate the effect of free surfaces on the transformation kinetics, the thin films and nanopillars simulation results are compared to bulk simulation results of cell size $8 \mathrm{~nm} \times 8 \mathrm{~nm} \times 8 \mathrm{~nm}$ (76532 atoms) and periodic boundary conditions in all three directions. 
For all simulations, initially, pristine austenite B2 NiTi samples with crystallographic orientation [001] (vertical axis), [110], and [1ํㅣ] (horizontal axis) are considered. Simulations are performed within the temperature range from $50 \mathrm{~K}$ to $750 \mathrm{~K}$, with an interval of $10 \mathrm{~K}$ within the temperature range from $250 \mathrm{~K}$ to $550 \mathrm{~K}$ and with $50 \mathrm{~K}$ interval for the remaining temperature range. Such large temperature range is considered so that an accurate estimation of the size dependent transformation temperatures, that is, martensite start $\left(M_{s}\right)$ and finish $\left(M_{f}\right)$ and phase fraction evolution, is obtained, which is important for obtaining, as detailed subsequently, the overall martensite phase fraction evolution in NiTi thin films and nanopillars as a function of temperature.

First, a pristine austenite B2 NiTi sample is relaxed using a stress controlled conjugate gradient energy minimization method. Then, the relaxed sample is given a velocity distribution corresponding to a particular temperature and held for 360 ps, under an NPT stabilization where the system pressure is kept constant at 0 bar. Then, the NPT stabilized sample is subjected to constant volume (NVT) conditions for an additional 240 ps. In each case of NPT or NVT stabilization, the adopted time step is 0.0005 ps. During simulation the temperature is controlled by a Nose-Hoover thermostat and Berendsen barostat. In order to remove the effects of thermal fluctuations, the atomic coordinates were averaged over $20 \mathrm{ps}$. It was verified that the systems were well-equilibrated and the fluctuations in total energy and temperature were smaller than $0.001 \mathrm{eV} /$ atom and $0.50 \mathrm{~K}$, respectively.

2.3. Structural Characterization. To distinguish austenite B2 phase from martensite $B 19^{\prime}$ phase and its variants, the bond length based order parameter proposed by Mutter and Nielaba $[31,44]$ was adopted. It can be expressed as

$$
\begin{aligned}
\chi & \left(d_{0}, d_{1}\right) \\
= & \frac{\left[d_{0}\left\{d^{(\mathrm{B} 2)}+d_{1}^{\left(\mathrm{B} 19^{\prime}\right)}\right\}\right]-\left[d_{1}\left\{d^{(\mathrm{B} 2)}+d_{0}^{\left(\mathrm{B} 19^{\prime}\right)}\right\}\right]}{\left[d^{(\mathrm{B} 2)}\left\{d_{0}^{\left(\mathrm{B} 19^{\prime}\right)}-d_{1}^{\left(\mathrm{B} 19^{\prime}\right)}\right\}\right]},
\end{aligned}
$$

where different bond length parameters of pure austenite phase and martensite phase are $d^{(\mathrm{B} 2)}=2.62 \AA, d_{0}^{\left(\mathrm{B} 19^{\prime}\right)}=$ $2.46 \AA$, and $d_{1}^{\left(\mathrm{B} 19^{\prime}\right)}=2.65 \AA$. The value of this order parameter becomes +1.0 for the martensite $\mathrm{B} 19^{\prime}$ phase when $d_{0}=$ $d_{0}^{\left(\mathrm{B} 19^{\prime}\right)}$ and $d_{1}=d_{1}^{\left(\mathrm{B} 19^{\prime}\right)}$. For the austenite B2 phase $d_{0}=$ $d_{1}=d^{(\mathrm{B} 2)}$ and thus the value of this order parameter becomes -1.0 . However, after simulation, lattice parameters of B2 and B19' phases change because of the linear thermal expansion or contraction $(\alpha \Delta T)$ and because of the internal strains $\left(\varepsilon^{*}\right)$ that develop during the phase transformation process. Thus, instead of showing distinct values (like delta function) at +1.0 (for B19' phase) or -1.0 (for B2 phase), this bond length based order parameter for ${\mathrm{B} 19^{\prime}}^{\prime}$ and $\mathrm{B} 2$ phase exhibits a narrow Gaussian distribution around +1.0 and -1.0 , respectively $[31,44,59]$. Therefore, to distinguish between the austenite

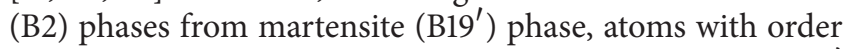
parameter greater than +0.75 correspond to martensite $\mathrm{B}^{\prime} 9^{\prime}$ phase and less than -0.75 to austenite B2 phase. It has been observed that this order parameter shows Gaussian distribution around a mean of $\mu_{\chi}= \pm\left(1 \pm \alpha \Delta T \pm \varepsilon^{*}\right)$ and a standard deviation $\sigma_{\chi}=\sqrt{(\alpha \Delta T)^{2}+\left(\varepsilon^{*}\right)^{2}}$. At every temperature and size, the martensite phase fraction was calculated by taking the ratio of intensity and spread in the Gaussian distributions. Further detailed description of the martensite phase fraction calculation based on this order parameter is provided in Mutter and Nielaba [31, 44].

2.4. Phase Transformation Kinetics. Phase fraction evolution kinetics in NiTi SMA is a very complex process that involves the competition between developed internal strain and phonon dispersion instability [1-4]. The rather limited studies reported in the literature mostly address the behavior of single crystals at small scales (quantum or atomic level). There are significant size effects present at small scales [11, 21$25,31,39,44]$ that add to the complexity and saturate at length scales in the range of several nanometers. Several works based on continuum thermodynamics address the macroscale constitutive behavior of NiTi and other SMAs subjected to thermomechanical loading [60-62]. In those studies, the phase fraction evolution is obtained directly from experimental results or is assumed empirically. Recently Zotov et al. [35] reported extensive experimental data on thermally induced martensitic phase fraction for bulk NiTi. Based on these experimental data on polycrystalline (mainly [110] B2 crystal with some [1111] B2 crystal) and annealed (at $750^{\circ} \mathrm{C}$ ) $\mathrm{NiTi}$ SMA, Zotov et al. [35] proposed a phenomenological model and verified it with respect to additional experimental data reported in the literature for NiTi of different concentrations of $\mathrm{Ni}$ and $\mathrm{Ti}[34,35]$. In the Zotov et al. [35] study, the experiments are performed with $20^{\circ} \mathrm{C} / \mathrm{min}$ cooling and heating rate. In this model, the austenite transformation rate at any given temperature is assumed to be proportional to the nucleation rate of austenite per unit volume. It is also assumed that the size of austenite nucleus increases linearly with the austenite phase fraction. This phenomenological model captures adequately the kinetics of the observed martensitic phase transformation rate as a function of the martensite phase fraction in the reported experiments. According to the model, the temperature dependent martensite phase fraction evolution is described through the Richards equation; that is,

$$
\xi(T)=1-\left[1+\exp \left\{-g \cdot v\left(T-T_{m}\right)\right\}\right]^{(-1 / v)},
$$

where $\xi(T)$ denotes the temperature dependent martensite phase fraction, $T$ the temperature of interest in degrees Kelvin, and $T_{m}$ the temperature corresponding to maximum transformation rate in degrees Kelvin, while $v$ (unit less) and $g($ in $1 / K)$ are fit parameters which dictate the transformation or growth rate of the martensite phase. Here, the nonlinear curve fitting tool box in MATLAB 2014b has been used to obtain the optimal value of different parameters in (4), where a nonlinear least square minimization technique is employed.

In the present study, for estimation of the martensite start $\left(M_{s}\right)$ and martensite finish $\left(M_{f}\right)$ temperatures, a range between $5 \%$ and $95 \%$ is considered. This is because, below $5 \%$ and beyond $95 \%$ of martensite phase fraction, it is observed that the standard deviation associated with the 


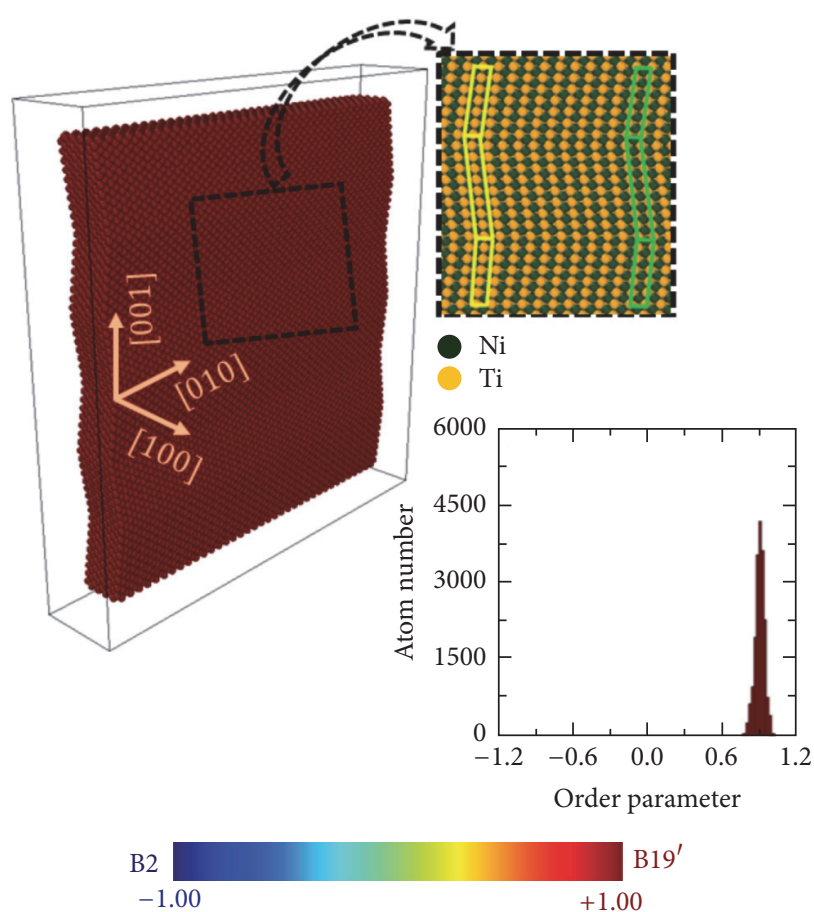

(a) $T=200 \mathrm{~K}$

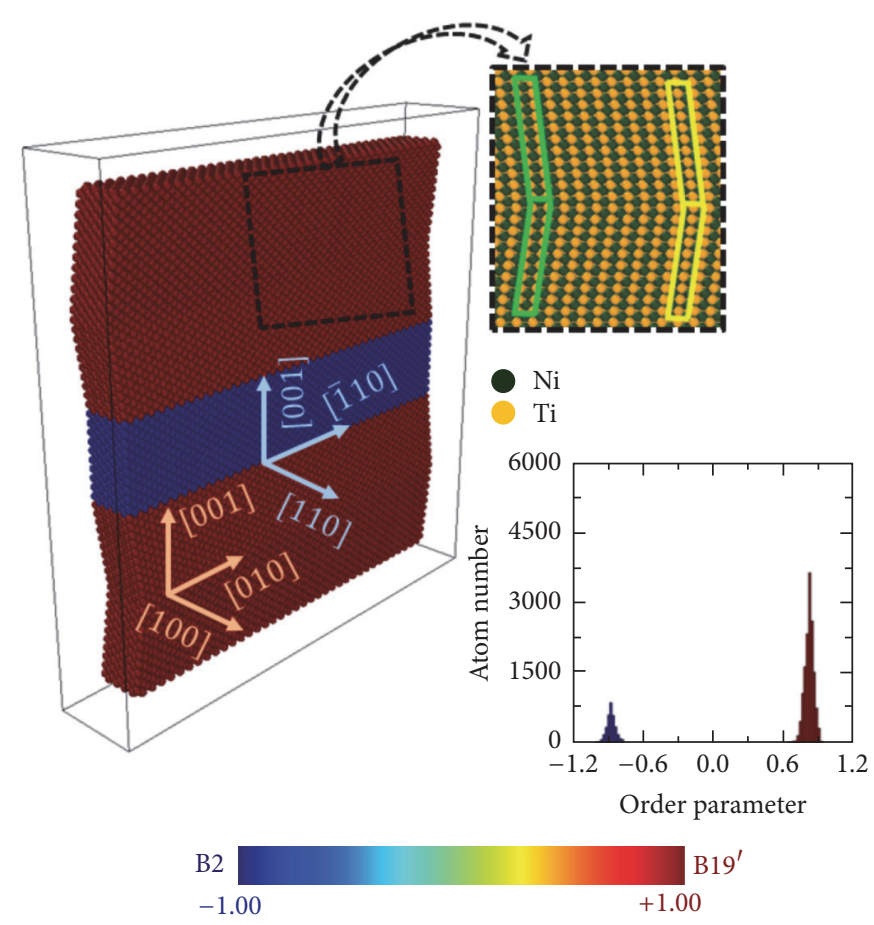

(b) $\mathrm{T}=350 \mathrm{~K}$

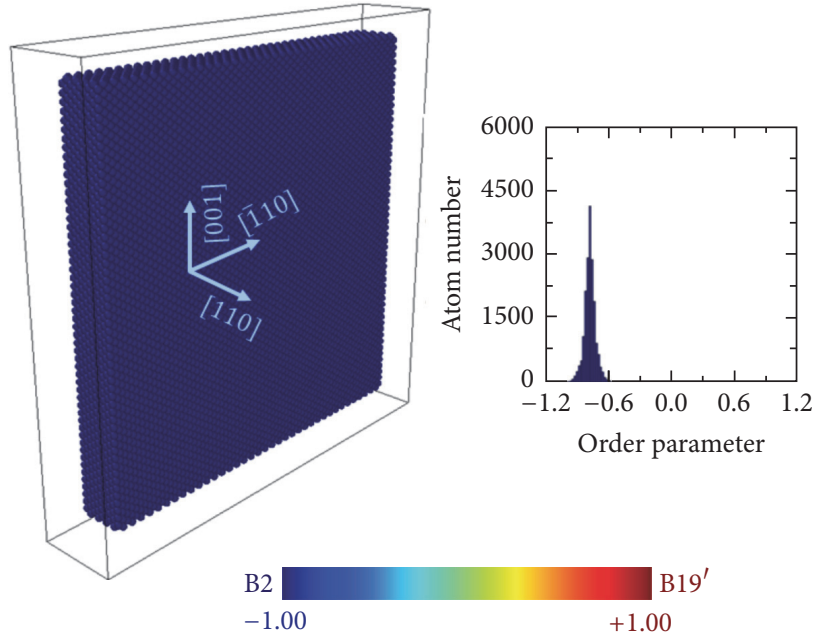

(c) $T=500 \mathrm{~K}$

Figure 1: Microstructure of the NiTi thin films for simulation cell size $8 \mathrm{~nm} \times 8 \mathrm{~nm} \times 2 \mathrm{~nm}$, stabilized at different temperatures (a) $T=200 \mathrm{~K}$, (b) $T=350 \mathrm{~K}$, and (c) $T=500 \mathrm{~K}$, depicting the martensite (B2) phase (in blue) and austenite (B19') phase (in red). The crystallographic orientations of $\mathrm{B} 2$ and $\mathrm{B} 19^{\prime}$ are marked by arrows in the respective phase regions.

estimated fraction of the minor phase is of the order of phase fraction of the major phase itself. Thus, using these limits in martensite phase fraction and (4), the estimated values for transformation temperatures, that is, $M_{s}$ and $M_{f}$, are expressed as

$$
M_{s}=T(\xi=0.05)=T_{m}-\left[\frac{\ln \left\{(0.95)^{-v}-1\right\}}{(g \cdot v)}\right],
$$

$$
M_{f}=T(\xi=0.95)=T_{m}-\left[\frac{\ln \left\{(0.05)^{-v}-1\right\}}{(g \cdot v)}\right] .
$$

A larger temperature range is included in this study in order to obtain accurate parameters for Richard's equation (i.e., $g, v$, and $\left.T_{m}\right)$, which describes the evolution of martensite phase fraction with temperature. Since Richard's equation (i.e., (4)) is highly nonlinear, to obtain accurate values for its parameters, nonlinear least square minimization is 


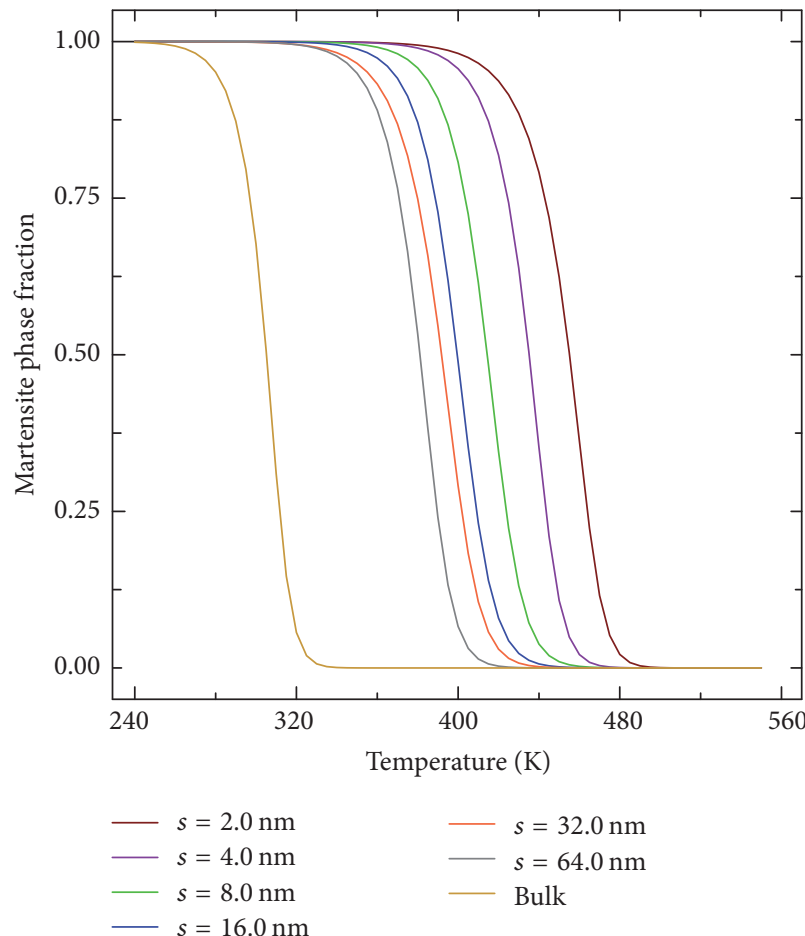

(a)

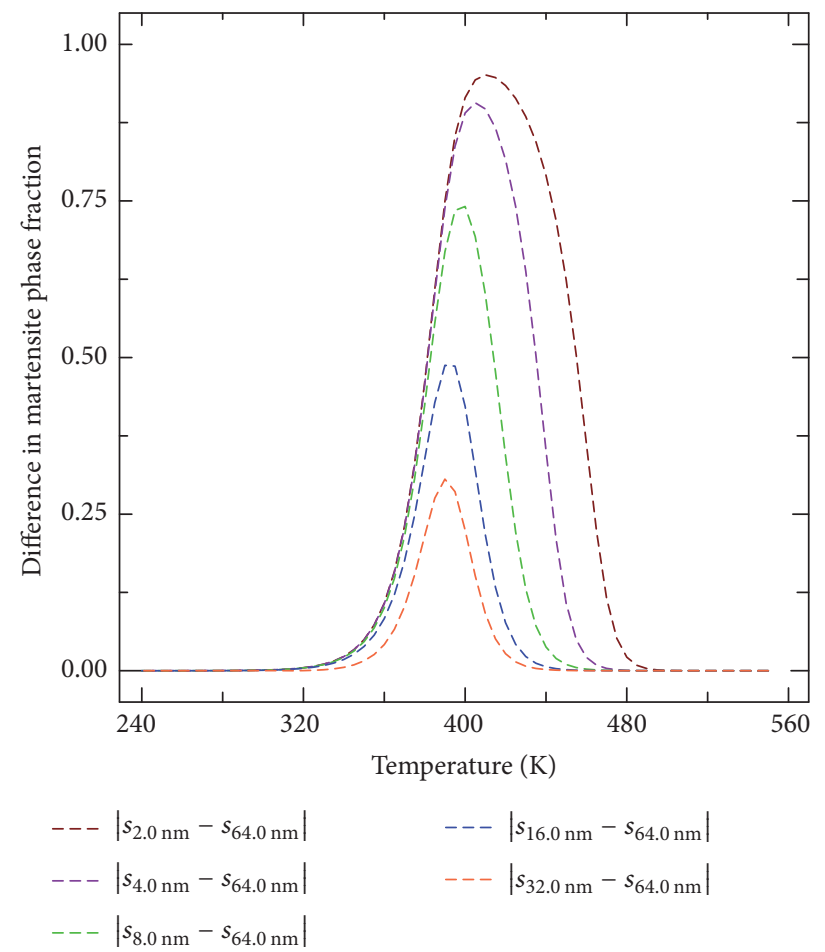

(b)

FIGURE 2: (a) Variation of the martensite phase fraction with respect to temperature for different sizes of MD thin film simulation cells and for bulk size. (b) Difference in martensite phase fraction between that in any size MD simulation cells and bulk size with respect to temperature.

performed, which requires a large number of data points for precise evaluation of the parameters. Further, the accurate evaluation of Richard's equation parameters is important for determining the martensite start $\left(M_{s}\right)$ and finish $\left(M_{f}\right)$ temperatures, in (5a) and (5b).

\section{Results and Discussions}

3.1. NiTi Thin Films. As mentioned above, quasi-static MD simulations are performed on NiTi thin films with free boundary conditions in all three directions for side sizes of $2,4,8,16,32$, and $64 \mathrm{~nm}$ with thickness $2 \mathrm{~nm}$ for all sizes. Simulations are performed within the temperature range from $50 \mathrm{~K}$ to $750 \mathrm{~K}$, with an interval of $10 \mathrm{~K}$ within the temperature range of 250 to $550 \mathrm{~K}$ and with $50 \mathrm{~K}$ interval for the remaining temperature range.

Figure 1 shows the microstructure of NiTi thin film at three different temperatures, 200, 350, and $500 \mathrm{~K}$, for $8 \mathrm{~nm}$ size. The microstructure at $200 \mathrm{~K}$, Figure 1(a), shows a single-phase martensite with (001) compound twins, and this is in good agreement with earlier work reported by Zhong et al. [11, 23]. As shown in Figure 1(b), at $350 \mathrm{~K}$ the microstructure shows a two-phase mixture wherein the (001) plane forms the interface (i.e., the habit plane) between the austenite and martensite phases, as reported in Zhong et al. [11, 23]. Further, the formation of the (001) habit plane is attributed to a combination of shear along the basal (on

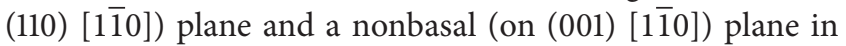
austenite, in agreement with what is reported in literature
[1, 14-17]. Figure 1(c) shows a single-phase austenite at $500 \mathrm{~K}$ temperature.

For every case an inset shows the order parameter distribution. As expected and discussed earlier, for Figure 1(a) (i.e., pure martensite phase) and Figure 1(c) (i.e., pure austenite phase) the order parameter shows a narrow Gaussian distribution around +1 and -1 , respectively. However, for Figure 1(b), that is, for two-phase mixture case order parameter shows two Gaussian distributions, with peaks around +1 and -1 , which is due to the coexistence of martensite and austenite phases.

Figure 2(a) shows the variation of martensite phase fraction with respect to temperature for different NiTi thin film sizes and for NiTi bulk. Since the martensite phase fraction curves (for different size) in Figure 2(a) are close to each other, it is difficult to directly obtain quantitative measure of the martensite phase fraction changes with respect to the simulation sample size. However, qualitatively it can be mentioned that with increasing size the martensite phase fraction decreases monotonically. In order to provide a protuberant indication of size effects on the phase transformation process, Figure 2(b) is provided. Here, the differences between the martensite phase fraction for a MD simulation cell size and that from the maximum size of thin film (i.e., $64 \mathrm{~nm}$ side length) at different temperatures are estimated.

Prominent size effects are observed. However, outside the transformation temperature zone differences in the martensite phase fraction diminish. These size effects can be explained from the available free surface area per unit 


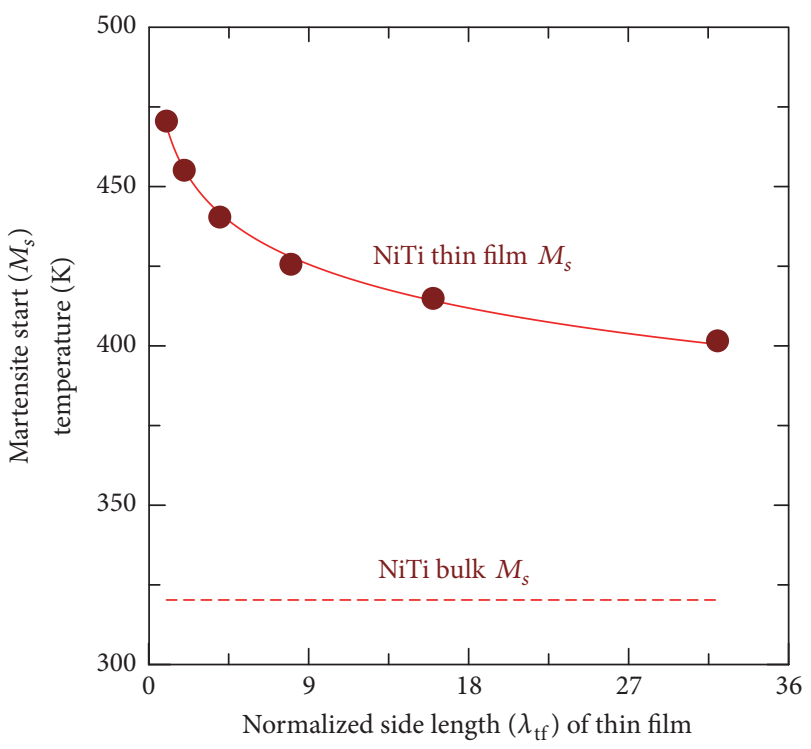

(a)

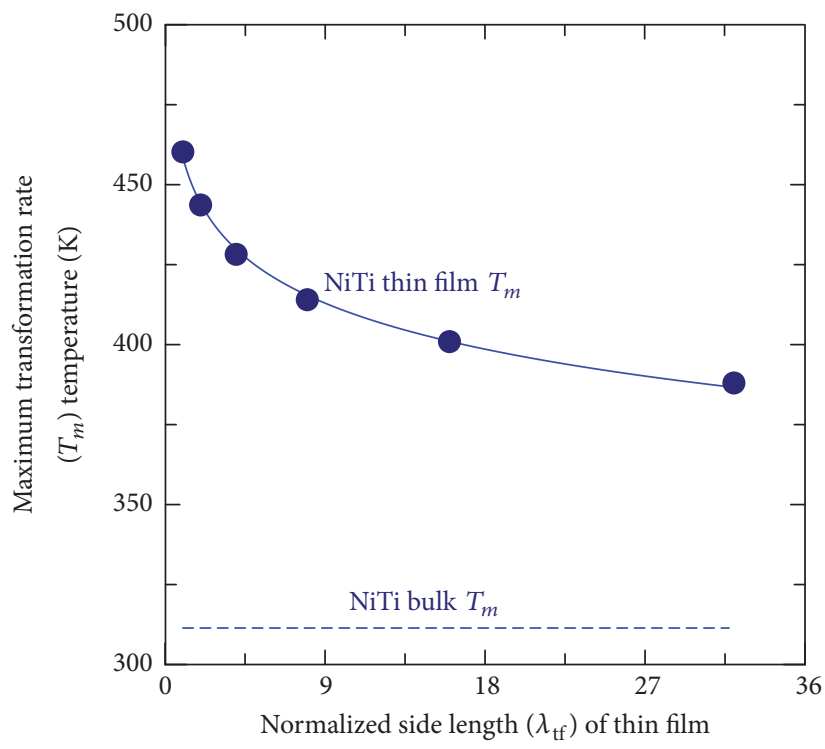

(b)

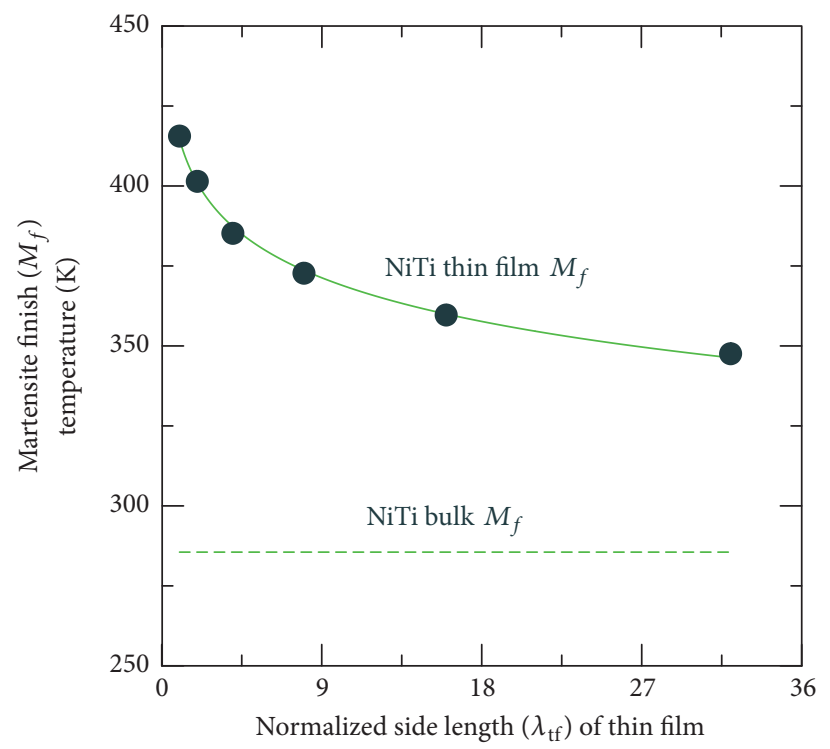

(c)

FIGURE 3: Variation of different transformation temperatures of thin films, with respect to the normalized side length $\left(\lambda_{\mathrm{tf}}=s / t\right)$ of the simulation cell for (a) martensite start $\left(M_{s}\right)$, (b) maximum transformation rate $\left(T_{m}\right)$, and (c) martensite finish $\left(M_{f}\right)$.

volume, which is directly associated with the free surface energy. The available free surface area per unit volume of a thin film can be expressed as

$$
\gamma=\frac{A}{V}=\left(\frac{2}{t}\right)+\left(\frac{4}{s}\right)
$$

where $t$ is the thickness of the film and $s$ is the side length of the film. Thus for a fixed thickness, the available free surface per unit volume is inversely proportional to its side length; that is, $A / V=\gamma \propto 1 / s$ and with the increase in size this quantity decreases inversely proportional to the square of the size; that is,

$$
\frac{d(A / V)}{d s}=\frac{d \gamma}{d s} \propto-\frac{1}{s^{2}}
$$

Now, the available free surface area per unit volume can be linked to the availability of free surface energy per unit volume for transforming the austenite (B2) phase into martensite phase (i.e., different $\mathrm{B} 19^{\prime}$ variants). Assuming that energy reduces due to the presence of free surface area as $e_{s}$ (per unit surface), the drop in the free energy density will be $\{(2 / t)+(4 / s)\} e_{s}$ (per unit volume). Thus, fixing the 


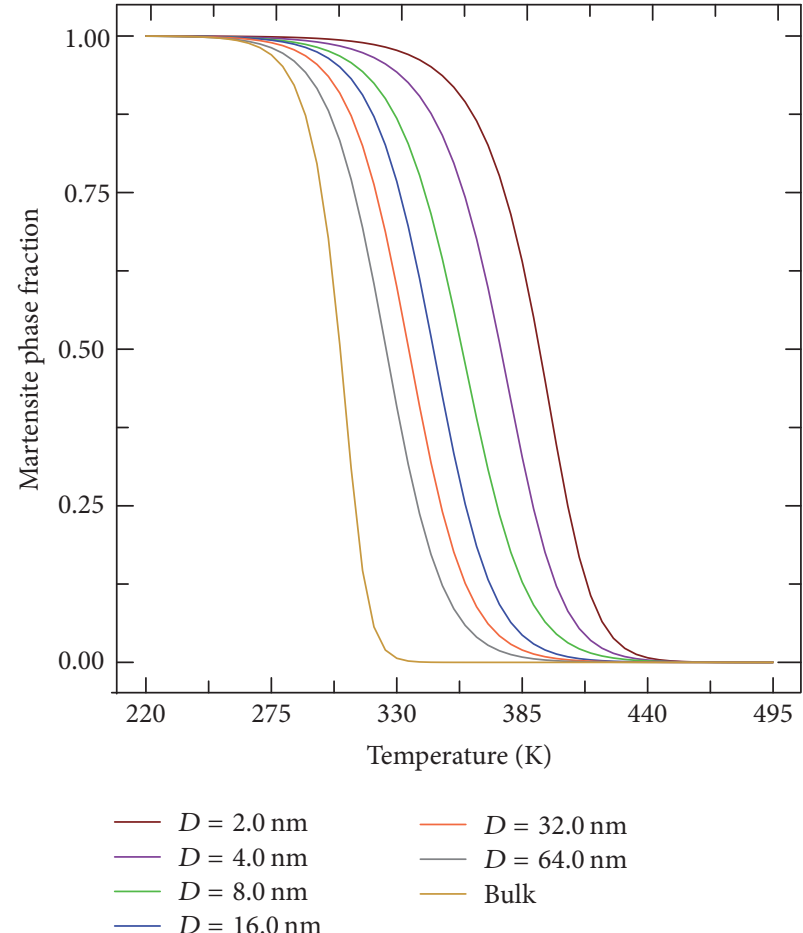

(a)

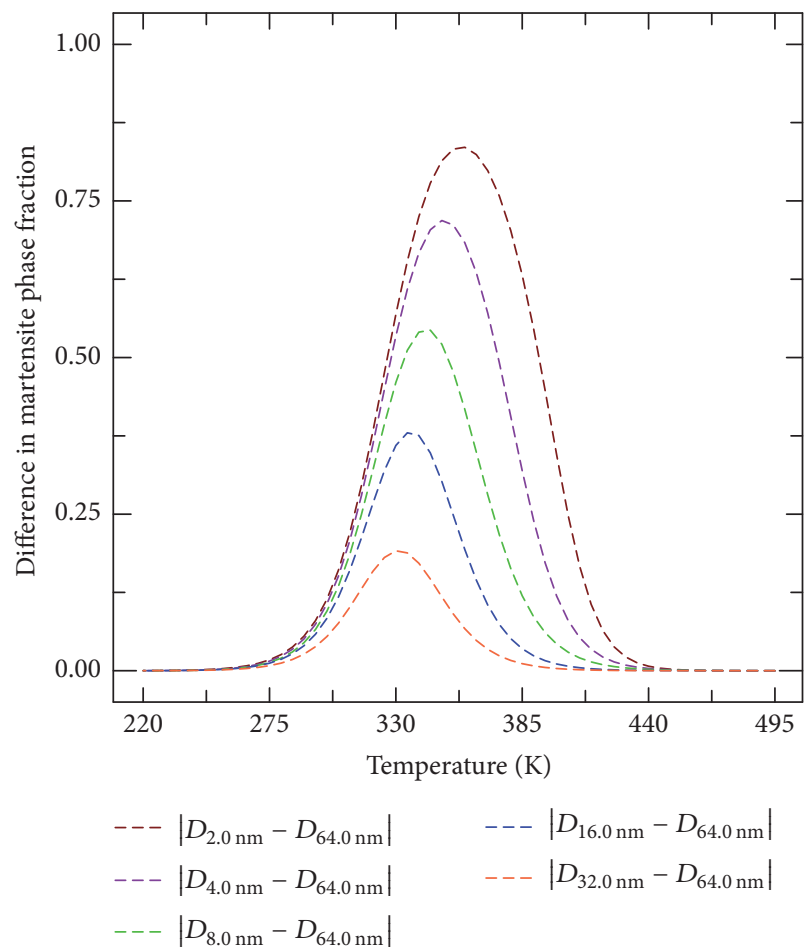

(b)

FiguRE 4: (a) Variation of the martensite phase fraction with respect to temperature for different nanopillar cell sizes and bulk size. (b) Difference in martensite phase fraction between that in various simulation cell sizes and that in bulk size, with respect to temperature.

thickness $t$, with decreasing size $s$, the drop in the free energy increases. This finally drives B2 to transform into B19' at much higher temperature in case of bulk NiTi. Therefore, at a fixed temperature, decreasing size results in more austenite transforming to martensite.

The martensite start $\left(M_{s}\right)$, maximum transformation rate $\left(T_{m}\right)$, and martensite finish $\left(M_{f}\right)$ temperatures for different thin film cell sizes are shown in Figure 3. For each cell size, the results are compared to those from the bulk simulation size. For bulk NiTi, the transformation temperatures are approximately $320 \mathrm{~K}$ for the martensite start $\left(M_{s}\right)$ and $285 \mathrm{~K}$ for the martensite finish $\left(M_{f}\right)$. A recent MD study on bulk NiTi reports martensite start and finish temperatures as $310 \mathrm{~K}$ and $290 \mathrm{~K}$, respectively $[11,12]$.

It can be observed that all transformation temperatures decrease with size and asymptotically converge to their value for bulk size. Size dependency of these transformation temperatures follows a logarithmic trend and a very good fit is $\psi_{\mathrm{tf}}=a_{\mathrm{tf}} \ln \left(\lambda_{\mathrm{tf}}\right)+b_{\mathrm{tf}}$, where $\lambda_{\mathrm{tf}}=s / t$ is the normalized side length with respect to the thickness, $\psi_{\text {tf }}$ represents any parameters $M_{s}, T_{m}$ or $M_{f}$ and $a_{\mathrm{tf}}, b_{\mathrm{tf}}$ are constants. It is important to mention that some previous MD based studies $[25,31]$ on NiTi nanoparticles, employing similar interatomic potential, demonstrate that transformation temperatures decrease linearly with size of the MD simulation cell. Such deviation in the results from these previous studies is due to the temperature rate dependent MD simulations that these studies performed, which are coupled to size effect, whereas, in the present study, simulations are performed at constant temperature. This aspect is interesting, and studies on this would be interesting, yet they are out of the scope of the present study.

3.2. NiTi Nanopillars. As mentioned above, quasi-static MD simulations are performed on NiTi nanopillars with free boundary in all three directions for diameters of 2, 4, 8, 16, 32 , and $64 \mathrm{~nm}$ and length of $8 \mathrm{~nm}$ for all cells. Simulations are performed within the temperature range from $50 \mathrm{~K}$ to $750 \mathrm{~K}$, with an interval of $10 \mathrm{~K}$ within the temperature range of 250 to $550 \mathrm{~K}$ and with $50 \mathrm{~K}$ interval for the remaining temperature range. Here also similar microstructures as those in thin films are observed; therefore they are not shown. However, the temperature dependency and transformation temperatures show differences with that of the NiTi thin films, as shown below. Figure 4(a) shows the martensite phase fraction as a function of temperature for different sizes of nanopillars. From Figure 4(a), it can be observed that, with increasing size, the martensite phase fraction decreases monotonically. It is noted that a very recent MD based study on NiTi nanowires, employing similar interatomic potential, demonstrates that evolution of martensite phase fraction decreases with size [24]; the discussion above with respect to thin films also holds here. Figure 4(b) shows the relevant size effects quantitatively, through the martensite phase fraction difference. The difference in the martensite phase fraction between that in various MD simulation cell sizes and that in 


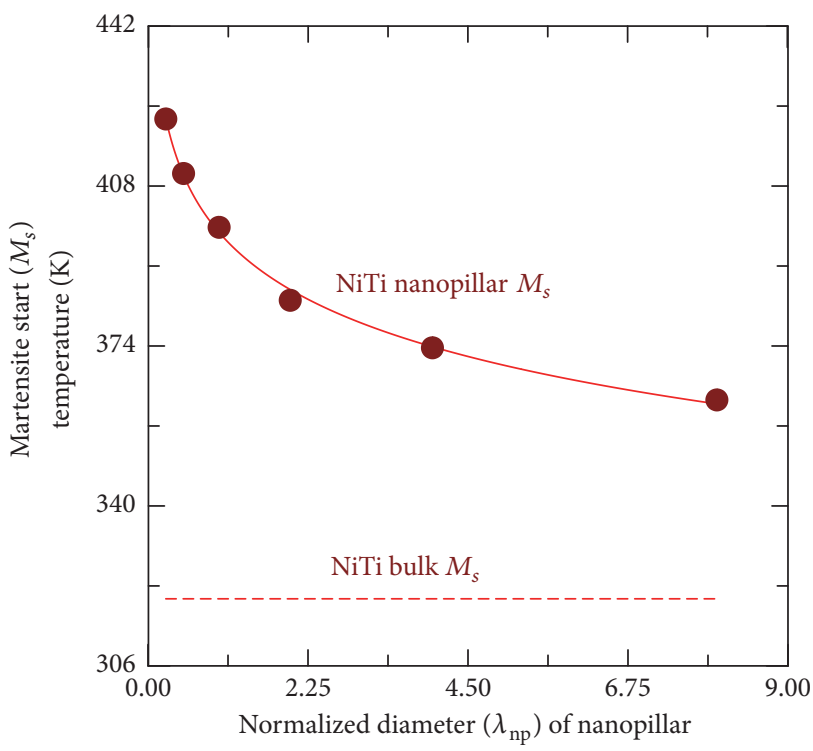

(a)

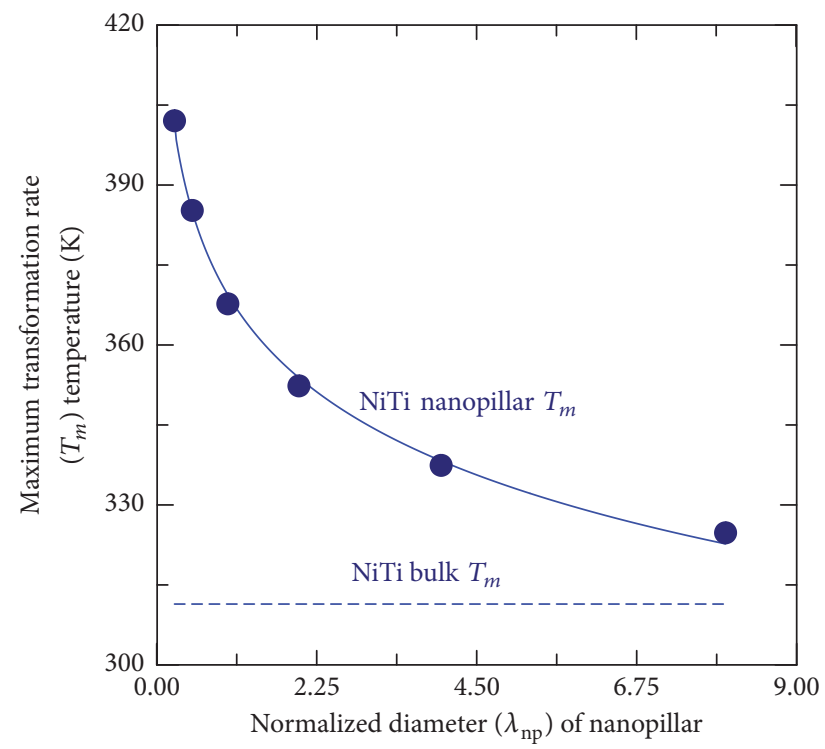

(b)

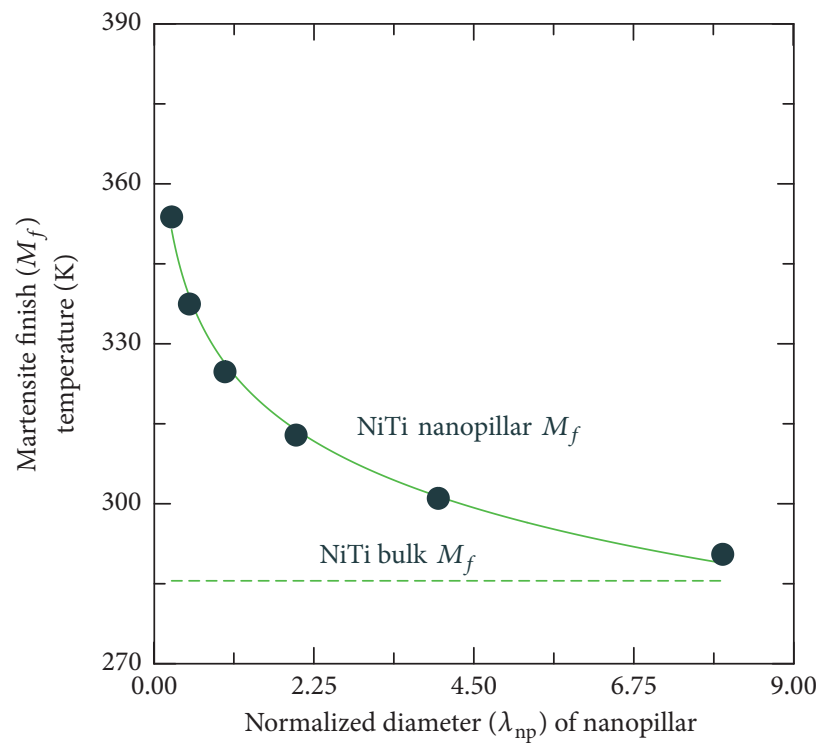

(c)

FIGURE 5: Variation of different transformation temperatures of nanopillars, with respect to the normalized diameter $\left(\lambda_{\mathrm{np}}=D / l\right)$ of the simulation cell for (a) martensite start $\left(M_{s}\right)$, (b) maximum transformation rate $\left(T_{m}\right)$, and (c) martensite finish $\left(M_{f}\right)$.

cell size (diameter) $64 \mathrm{~nm}$ at different temperatures is estimated.

Similarly to thin films, within the transformation temperature zone size effects are very prominent, while outside the transformation temperature zone this difference in the martensite phase fraction diminishes. Here also the size effect can be linked to the available free surface area per unit volume and the associated free surface energy. The available free surface area per unit volume of a nanopillar can be expressed as

$$
\frac{A}{V}=\gamma=\left(\frac{1}{D}\right)+\left(\frac{1}{2 l}\right)
$$

where $D$ is the diameter of the pillar and $l$ is the height of the nanopillars. Therefore, for fixed length $l$, the free surface area per unit volume is inversely proportional to the diameter; that is, $A / V=\gamma \propto(1 / D)$ and with the increase in size (i.e., diameter) this quantity decreases inversely proportional to the square of the diameter of the nanopillar; that is,

$$
\frac{d(A / V)}{d D}=\frac{d \gamma}{d D} \propto-\frac{1}{D^{2}} \text {. }
$$

The free surfaces can be linked to the drop in free energy density, which is $\{(1 / D)+(1 / 2 l)\} e_{s}$ (per unit volume). By simply considering $D=t$ and $l=s$, it can be observed that the drop in free energy density caused by the free surface in NiTi nanopillars is different than in thin films. Therefore, the phase fraction evolution and transformation temperatures are different in nanopillars compared to those in thin films. 
Further, from Figure 4(a) it can be clearly observed that the martensite phase fraction evolution curves for nanopillars are much closer to the bulk than those of the thin films. This is because of the fact that, for same size of thin films and nanopillars, thin films have much more effective surface area per unit volume (i.e., $\gamma=A / V$ ) than nanopillars. Free surfaces act as defects and thus cause more drop in free energy density in NiTi thin films than in nanopillars. This ultimately causes early transformation from $\mathrm{B} 2$ to $\mathrm{B} 19^{\prime}$ in NiTi thin films compared to nanopillars, at high temperature.

From the martensite phase fraction evolution curves, as shown in Figure 4(a), the transformation temperatures, that is, martensite start $\left(M_{s}\right)$, maximum transformation rate $\left(T_{m}\right)$, and martensite finish $\left(M_{f}\right)$ temperatures for different sizes, are estimated and shown in Figure 5 and compared to those for the bulk size. In Figure 5, the normalized diameter (with respect to the height) of the nanopillars is defined as $\lambda_{\text {np }}=$ $D / l$. Transformation temperatures decrease logarithmically with increasing size and asymptotically converge to their values for bulk size. Similarly to thin films, a very good fit for the size dependency of the transformation temperatures is $\psi_{\mathrm{np}}=a_{\mathrm{np}} \ln \left(\lambda_{\mathrm{np}}\right)+b_{\mathrm{np}}$, where $\lambda_{\mathrm{np}}=D / l, \psi_{\mathrm{np}}$ represents parameters $M_{s}, T_{m}$ or $M_{f}$, and $a_{\mathrm{np}}, b_{\mathrm{np}}$ are constants.

\section{Conclusions}

The present study demonstrates the size effects at the atomic level in the thermally induced martensitic phase transformation process. Two different geometric structures (a) thin films and (b) nanopillars are considered and classical MD simulations are performed at different (constant) temperatures and for different sizes, employing well-established interatomic potential for NiTi SMA. Results show strong size effects, which are linked to the presence of free surfaces. As opposed to bulk NiTi, by changing the size of NiTi thin films or nanopillars it is possible to change the transformation temperature regime substantially. With increasing size of NiTi thin films or nanopillars, the transformation temperatures approach the value for bulk size. For every case and size, it is observed that the temperature dependent martensite phase fraction evolution can be expressed through Richard's equation with different phenomenological model parameters. Parameters such as the martensite start temperature $\left(M_{s}\right)$, maximum transformation rate $\left(T_{m}\right)$, and martensite finish temperature $\left(M_{f}\right)$ monotonically decrease with increasing size and follow a logarithmic trend with the simulation cell size. Results from the present study provide new insight for designing NiTi SMA based sensors, actuators, or devices at nano- to micrometer scale.

\section{Competing Interests}

The authors declare that they have no competing interests.

\section{Acknowledgments}

The reported exploratory work became possible through the support of Sourav Gur by the University of Arizona. Also the authors would like to acknowledge Professor Ting Zhu (from
Woodruff School of Mechanical Engineering at Georgia Institute of Technology) for providing the interatomic potential parameters.

\section{References}

[1] T. Tadaki, K. Otsuka, and K. Shimizu, "Shape memory alloys," Annual Review of Materials Science, vol. 18, no. 1, pp. 25-45, 1988.

[2] G. L. Zhao and B. N. Harmon, "Electron-phonon interactions and the phonon anomaly in $\beta$-phase NiTi," Physical Review B, vol. 48, no. 4, pp. 2031-2036, 1993.

[3] N. Hatcher, O. Y. Kontsevoi, and A. J. Freeman, "Role of elastic and shear stabilities in the martensitic transformation path of NiTi," Physical Review B-Condensed Matter and Materials Physics, vol. 80, no. 14, Article ID 144203, 2009.

[4] N. A. Zarkevich and D. D. Johnson, "Shape-memory transformations of NiTi: minimum-energy pathways between austenite, martensites, and kinetically limited intermediate states," Physical Review Letters, vol. 113, no. 26, pp. 265701-265705, 2014.

[5] J. Van Humbeeck, "Non-medical applications of shape memory alloys," Materials Science and Engineering A, vol. 273-275, pp. 134-148, 1999.

[6] T. Duerig, A. Pelton, and D. Stöckel, "An overview of nitinol medical applications," Materials Science and Engineering A, vol. 273-275, pp. 149-160, 1999.

[7] G. Song, N. Ma, and H.-N. Li, "Applications of shape memory alloys in civil structures," Engineering Structures, vol. 28, no. 9, pp. 1266-1274, 2006.

[8] K. F. Hane, "Bulk and thin film microstructures in untwinned martensites," Journal of the Mechanics and Physics of Solids, vol. 47, no. 9, pp. 1917-1939, 1999.

[9] K. F. Hane and T. W. Shield, "Microstructure in the cubic to monoclinic transition in titanium-nickel shape memory alloys," Acta Materialia, vol. 47, no. 9, pp. 2603-2617, 1999.

[10] R. D. James and K. F. Hane, "Martensitic transformations and shape-memory materials," Acta Materialia, vol. 48, no. 1, pp. 197-222, 2000.

[11] Y. Zhong, K. Gall, and T. Zhu, "Atomistic study of nanotwins in NiTi shape memory alloys," Journal of Applied Physics, vol. 110, no. 3, Article ID 033532, 2011.

[12] Y. Zhong and T. Zhu, "Phase-field modeling of martensitic microstructure in NiTi shape memory alloys," Acta Materialia, vol. 75, pp. 337-347, 2014.

[13] K. M. Knowles and D. A. Smith, "The crystallography of the martensitic transformation in equiatomic nickel-titanium," Acta Metallurgica, vol. 29, no. 1, pp. 101-110, 1981.

[14] K. Otsuka and X. Ren, "Recent developments in the research of shape memory alloys," Intermetallics, vol. 7, no. 5, pp. 511-528, 1999.

[15] K. Otsuka and X. Ren, "Martensitic transformations in nonferrous shape memory alloys," Materials Science and Engineering A, vol. 273-275, pp. 89-105, 1999.

[16] X. Ren, N. Miura, K. Taniwaki et al., "Understanding the martensitic transformations in TiNi-based alloys by elastic constants measurement," Materials Science and Engineering A, vol. 273-275, pp. 190-194, 1999.

[17] K. Otsuka and X. Ren, "Physical metallurgy of Ti-Ni-based shape memory alloys," Progress in Materials Science, vol. 50, no. 5, pp. 511-678, 2005. 
[18] Q. Meng, H. Yang, Y. Liu, and T.-H. Nam, “Transformation intervals and elastic strain energies of $\mathrm{B} 2-\mathrm{B} 19^{\prime}$ martensitic transformation of NiTi," Intermetallics, vol. 18, no. 12, pp. 2431-2434, 2010.

[19] Y. Chen and C. A. Schuh, "A coupled kinetic Monte Carlo-finite element mesoscale model for thermoelastic martensitic phase transformations in shape memory alloys," Acta Materialia, vol. 83, pp. 431-447, 2015.

[20] J. W. Christian and S. Mahajan, "Deformation twinning," Progress in Materials Science, vol. 39, no. 1-2, pp. 1-157, 1995.

[21] T. Waitz, D. Spišák, J. Hafner, and H. P. Karnthaler, "Sizedependent martensitic transformation path causing atomicscale twinning of nanocrystalline NiTi shape memory alloys," Europhysics Letters, vol. 71, no. 1, pp. 98-103, 2005.

[22] T. Waitz, T. Antretter, F. D. Fischer, N. K. Simha, and H. P. Karnthaler, "Size effects on the martensitic phase transformation of NiTi nanograins," Journal of the Mechanics and Physics of Solids, vol. 55, no. 2, pp. 419-444, 2007.

[23] Y. Zhong, K. Gall, and T. Zhu, "Atomistic characterization of pseudoelasticity and shape memory in NiTi nanopillars," Acta Materialia, vol. 60, no. 18, pp. 6301-6311, 2012.

[24] R. Mirzaeifar, K. Gall, T. Zhu, A. Yavari, and R. Desroches, "Structural transformations in NiTi shape memory alloy nanowires," Journal of Applied Physics, vol. 115, no. 19, Article ID 194307, 2014.

[25] Z. Zhang, X. Ding, J. Deng et al., "Surface effects on structural phase transformations in nanosized shape memory alloys," The Journal of Physical Chemistry C, vol. 117, no. 15, pp. 7895-7901, 2013.

[26] G. Frantziskonis and I. Vardoulakis, "On the micro-structure of surface effects and related instabilities," European Journal of Mechanics A: Solids, vol. 11, no. 1, pp. 21-34, 1992.

[27] H. Dai and G. Frantziskonis, "Heterogeneity, spatial correlations, size effects and dissipated energy in brittle materials," Mechanics of Materials, vol. 18, no. 2, pp. 103-118, 1994.

[28] G. Frantziskonis and P. Deymier, "The effects of stress concentrators on strength of materials at nanoscale: a molecular dynamics study," Mechanics Research Communications, vol. 33, no. 3, pp. 352-358, 2006.

[29] G. Frantziskonis and P. Deymier, "Surface effects at the nanoscale significantly reduce the effects of stress concentrators," Probabilistic Engineering Mechanics, vol. 21, no. 3, pp. 277-286, 2006.

[30] T. Waitz, W. Pranger, T. Antretter, F. D. Fischer, and H. P. Karnthaler, "Competing accommodation mechanisms of the martensite in nanocrystalline NiTi shape memory alloys," Materials Science and Engineering A, vol. 481-482, pp. 479-483, 2008.

[31] D. Mutter and P. Nielaba, "Simulation of the thermally induced austenitic phase transition in NiTi nanoparticles: simulation of phase transitions in NiTi nanoparticles," The European Physical Journal B, vol. 84, no. 1, pp. 109-113, 2011.

[32] K. Tsuchiya, M. Inuzuka, D. Tomus et al., "Martensitic transformation in nanostructured TiNi shape memory alloy formed via severe plastic deformation," Materials Science and Engineering A, vol. 438-440, pp. 643-648, 2006.

[33] J. S. Juan, M. L. Nó, and C. A. Schuh, "Nanoscale shape-memory alloys for ultrahigh mechanical damping," Nature Nanotechnology, vol. 4, no. 7, pp. 415-419, 2009.

[34] M. Pattabi, K. Ramakrishna, and K. K. Mahesh, "Effect of thermal cycling on the shape memory transformation behavior of
NiTi alloy: powder X-ray diffraction study,' Materials Science and Engineering A, vol. 448, no. 1-2, pp. 33-38, 2007.

[35] N. Zotov, V. Marzynkevitsch, and E. J. Mittemeijer, "Evaluation of kinetic equations describing the martensite-austenite phase transformation in NiTi shape memory alloys," Journal of Alloys and Compounds, vol. 616, pp. 385-393, 2014.

[36] T. Waitz, T. Antretter, F. D. Fischer, and H. P. Karnthaler, "Size effects on martensitic phase transformations in nanocrystalline NiTi shape memory alloys," Materials Science and Technology, vol. 24, no. 8, pp. 934-940, 2008.

[37] H. X. Li, S. C. Mao, K. T. Zang et al., "An in situ TEM study of the size effect on the thermally induced martensitic transformation in nanoscale NiTi shape memory alloy," Journal of Alloys and Compounds, vol. 588, pp. 337-342, 2014.

[38] Y. Q. Fu, S. Zhang, M. J. Wu et al., "On the lower thickness boundary of sputtered TiNi films for shape memory application," Thin Solid Films, vol. 515, no. 1, pp. 80-86, 2006.

[39] C.-D. Wu, P.-H. Sung, and T.-H. Fang, "Study of deformation and shape recovery of NiTi nanowires under torsion," Journal of Molecular Modeling, vol. 19, no. 4, pp. 1883-1890, 2013.

[40] H. Kahn, M. A. Huff, and A. H. Heuer, "The TiNi shapememory alloy and its applications for MEMS," Journal of Micromechanics and Microengineering, vol. 8, no. 3, pp. 213-221, 1998.

[41] M. Bendahan, K. Aguir, J.-L. Seguin, and H. Carchano, "NiTi thin films as a gate of M.O.S. capacity sensors," Sensors and Actuators, A: Physical, vol. 74, no. 1-3, pp. 242-245, 1999.

[42] M. Kohl, D. Dittmann, E. Quandt, and B. Winzek, “Thin film shape memory microvalves with adjustable operation temperature," Sensors and Actuators A: Physical, vol. 83, no. 1-3, pp. 214-219, 2000.

[43] P. M. Chan, C. Y. Chung, and K. C. Ng, "NiTi shape memory alloy thin film sensor micro-array for detection of infrared radiation," Journal of Alloys and Compounds, vol. 449, no. 1-2, pp. 148-151, 2008.

[44] D. Mutter and P. Nielaba, "Simulation of the shape memory effect in a NiTi nano model system," Journal of Alloys and Compounds, vol. 577, no. 1, pp. S83-S87, 2013.

[45] D. Mutter and P. Nielaba, "Simulation of structural phase transitions in NiTi," Physical Review B, vol. 82, no. 22, pp. 224201224209, 2010.

[46] Z. G. Wang, X. T. Zu, and Y. Huo, "Effect of heating/cooling rate on the transformation temperatures in $\mathrm{TiNiCu}$ shape memory alloys," Thermochimica Acta, vol. 436, no. 1-2, pp. 153-155, 2005.

[47] K. Nurveren, A. Akdogğan, and W. M. Huang, "Evolution of transformation characteristics with heating/cooling rate in $\mathrm{NiTi}$ shape memory alloys," Journal of Materials Processing Technology, vol. 196, no. 1-3, pp. 129-134, 2008.

[48] Y. Motemani, M. Nili-Ahmadabadi, M. J. Tan, M. Bornapour, and Sh. Rayagan, "Effect of cooling rate on the phase transformation behavior and mechanical properties of Ni-rich NiTi shape memory alloy," Journal of Alloys and Compounds, vol. 469, no. 1-2, pp. 164-168, 2009.

[49] Y.-Q. Zhang, S.-Y. Jiang, Y.-N. Zhao, and M. Tang, "Influence of cooling rate on phase transformation and microstructure of Ti-50.9\%Ni shape memory alloy," Transactions of Nonferrous Metals Society of China, vol. 22, no. 11, pp. 2685-2690, 2012.

[50] D. Wan and K. Komvopoulos, "Thickness effect on thermally induced phase transformations in sputtered titanium-nickel shape-memory films," Journal of Materials Research, vol. 20, no. 6, pp. 1606-1612, 2005. 
[51] R. M. S. Martins, N. Schell, A. Mücklich et al., "Study of graded Ni-Ti shape memory alloy film growth on Si(100) substrate," Applied Physics A: Materials Science and Processing, vol. 91, no. 2, pp. 291-299, 2008.

[52] N. Choudhary, D. K. Kharat, and D. Kaur, "Structural, electrical and mechanical properties of magnetron sputtered NiTi/ PZT/TiOx thin film heterostructures," Surface \& Coatings Technology, vol. 205, no. 11, pp. 3387-3396, 2011.

[53] W. S. Lai and B. X. Liu, "Lattice stability of some Ni-Ti alloy phases versus their chemical composition and disordering," Journal of Physics Condensed Matter, vol. 12, no. 5, pp. L53-L60, 2000.

[54] S. Plimpton, "Fast parallel algorithms for short-range molecular dynamics," Journal of Computational Physics, vol. 117, no. 1, pp. 1-19, 1995.

[55] S. Plimpton, "Computational limits of classical molecular dynamics simulations," Computational Materials Science, vol. 4, no. 4, pp. 361-364, 1995.

[56] S. Gur, S. K. Mishra, and G. N. Frantziskonis, "Thermo-mechanical strain rate-dependent behavior of shape memory alloys as vibration dampers and comparison to conventional dampers," Journal of Intelligent Material Systems and Structures, vol. 27, no. 9, pp. 1250-1264, 2016.

[57] T. Sato, K.-I. Saitoh, and N. Shinke, "Molecular dynamics study on microscopic mechanism for phase transformation of Ni-Ti alloy," Modelling and Simulation in Materials Science and Engineering, vol. 14, no. 5, pp. S39-S46, 2006.

[58] K.-I. Saitoh, T. Sato, and N. Shinke, "Atomic dynamics and energetics of martensitic transformation in nickel-titanium shape memory alloy," Materials Transactions, vol. 47, no. 3, pp. 742-749, 2006.

[59] S. Gur, V. R. Manga, S. Bringuier, K. Muralidharan, and G. Frantziskonis, Anisotropy in the Transformation Dynamics of Austenite (B2) to Martensite (B19') Associated with Superelasticity in NiTi, TMS Annual Meeting \& Exhibition, 2015.

[60] D. Helm and P. Haupt, "Shape memory behaviour: modelling within continuum thermomechanics," International Journal of Solids and Structures, vol. 40, no. 4, pp. 827-849, 2003.

[61] M. Panico and L. C. Brinson, "A three-dimensional phenomenological model for martensite reorientation in shape memory alloys," Journal of the Mechanics and Physics of Solids, vol. 55, no. 11, pp. 2491-2511, 2007.

[62] W. Zaki and Z. Moumni, "A three-dimensional model of the thermomechanical behavior of shape memory alloys," Journal of the Mechanics and Physics of Solids, vol. 55, no. 11, pp. 24552490, 2007. 

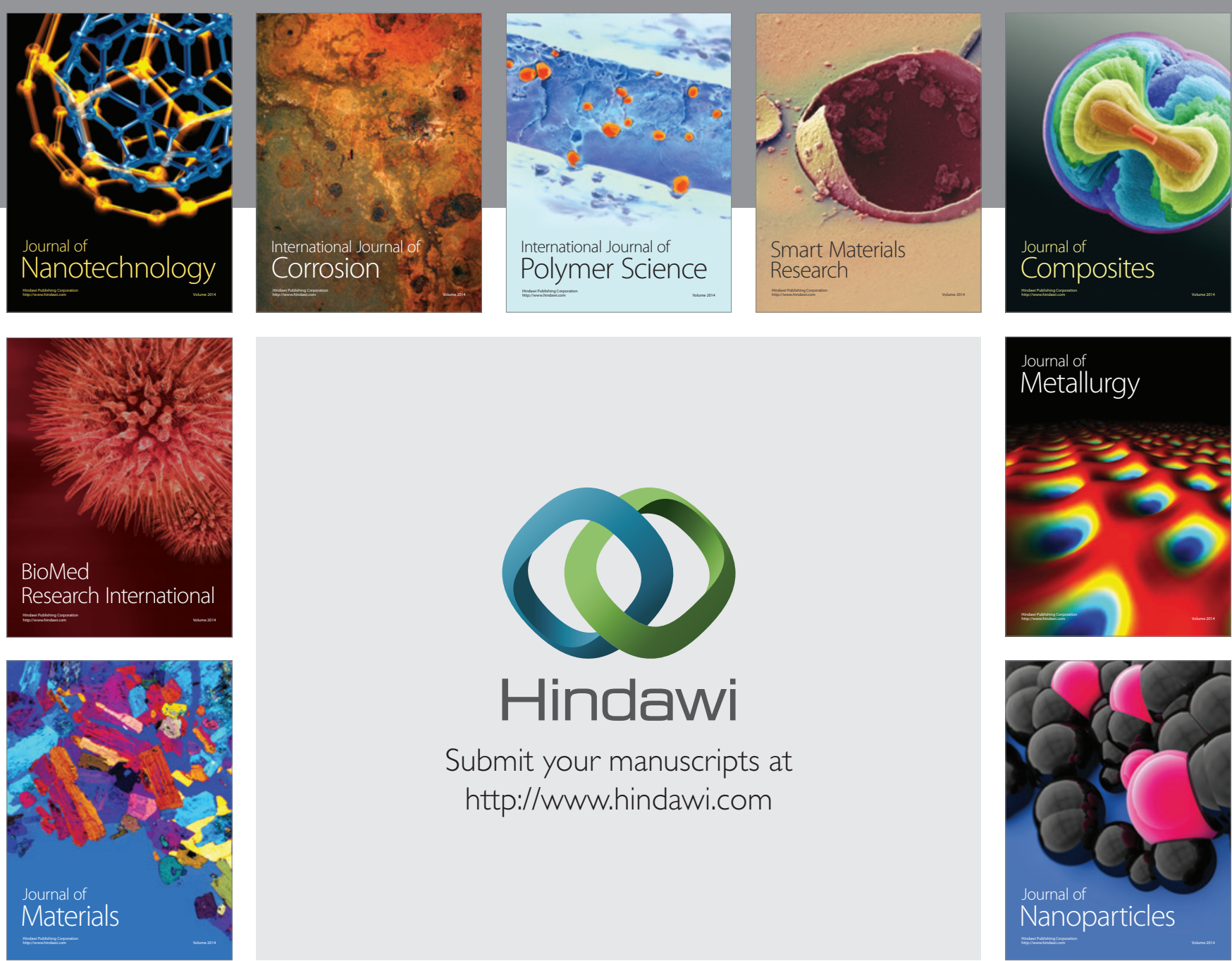

\section{Hindawi}

Submit your manuscripts at

http://www.hindawi.com

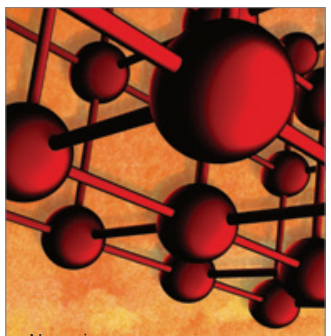

Materials Science and Engineering
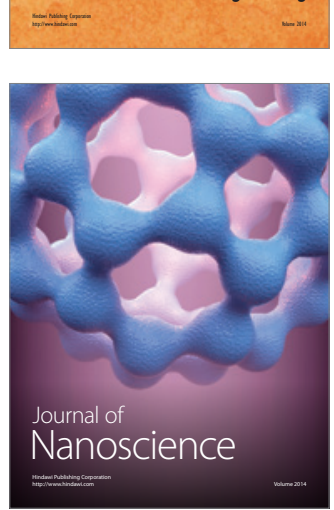
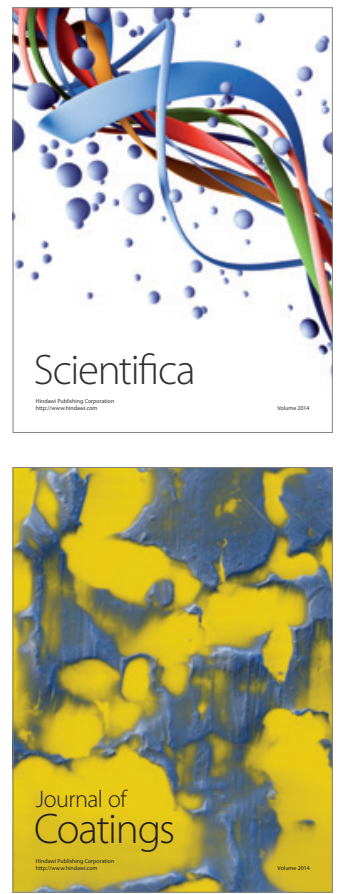
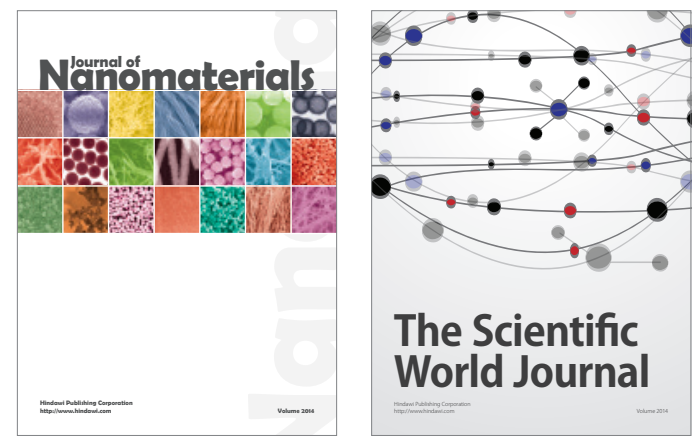

The Scientific World Journal
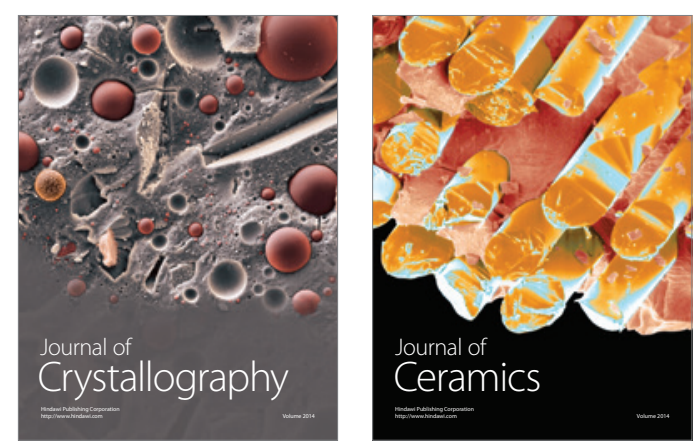
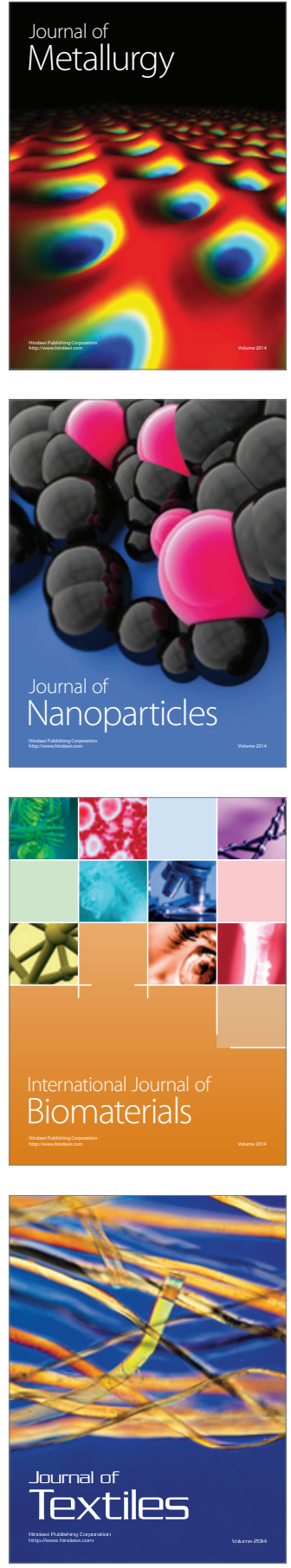